\title{
Effect of inspiratory flow rate on bronchomotor tone in normal and asthmatic subjects
}

\author{
W HIDA, M ARAI, C SHINDOH, Y-N LIU, H SASAKI, T TAKISHIMA \\ From the First Department of Internal Medicine, Tohoku University School of Medicine, Sendai, Japan
}

ABSTRACT The effect of the inspiratory flow rate during deep inspiration on the regulation of bronchomotor tone was studied in nine normal and 22 asthmatic subjects. Changes in bronchial tone were assessed by respiratory resistance measured by an oscillation method. In normal subjects with bronchoconstriction induced by methacholine a rapid deep inspiration reduced respiratory resistance more than a slow deep inspiration. Asthmatic subjects with spontaneous airway narrowing showed an increase in respiratory resistance after deep inspiration that was greater after rapid than after slow deep inspiration. On the other hand, in asthmatics with methacholine induced bronchoconstriction, bronchodilatation occurred after deep inspiration and this was also greater after rapid than after slow deep inspiration. Lignocaine inhalation attenuated both bronchoconstriction and bronchodilatation induced by both slow and rapid deep inspiration. These results suggest that the effects of deep inspiration are mediated at least in part via receptors in the airways. It is suggested that in asthmatic patients with spontaneous bronchoconstriction irritant receptor activity will be increased in proportion to the speed of inspiration. After methacholine induced bronchoconstriction stretch receptor activity is likely to behave in a similar fashion, leading to an opposite effect.

A deep inspiration has been reported to produce a transient decrease in airway calibre in some asthmatic subjects. ${ }^{2}$ In contrast, in the presence of pharmacologically induced bronchoconstriction a deep inspiration produces bronchodilatation in most asthmatic $^{3}$ and normal ${ }^{4}$ subjects. The reason for these divergent effects of deep inspiration on bronchomotor tone with and without drug induced bronchoconstriction is unclear. Deep inspiration might stimulate different vagal sensory receptors in these different circumstances: in those with artificially induced bronchoconstriction deep inspiration might stimulate stretch receptors, which induce bronchodilatation ${ }^{5}$; while in asthmatics without provoked bronchoconstriction deep inspiration might activate irritant receptors, inducing bronchoconstriction. $^{6}$ Recently, Beaupré and Orehek ${ }^{7}$ observed that a fast inspiratory flow rate induced more bronchodilatation than after inspiration with a slow inspiratory flow rate in asthmatic subjects with

Address for reprint requests: Dr Tamotsu Takishima, First Department of Internal Medicine, Tohoku University School of Medicine, Sendai, Japan 980.

Accepted 1 November 1983 carbachol induced bronchoconstriction, and they suggested that this might have been due to greater stimulation of stretch receptors at higher flows.

The inspiratory flow has not been controlled in previous studies reporting bronchoconstriction induced by deep inspiration. ${ }^{2}$ We therefore examined whether the flow rate during a deep inspiration affects bronchomotor tone in asthmatic patients with drug induced bronchoconstriction and with spontaneous bronchomotor tone. In addition, we examined the effects of rate of deep inspiration in asthmatic and normal subjects after pretreatment with lignocaine, which is known to block both irritant and stretch receptors. ${ }^{\mathrm{s}}$ We also examined whether any bronchoconstrictor effect of the speed of inspiratory flow was related to the degree of airway hypersensitivity as assessed by sensitivity to methacholine.

\section{Methods}

We studied nine normal men (mean age $28 \cdot 8$ (SEM $1 \cdot 7)$ years) and 22 patients with asthma ( 16 men and six women, mean age $38.8(3.4)$ years) who were diagnosed on clinical and functional criteria. ${ }^{.}$None was having long term steroid treatment. All were 
symptomless at the time of study, and no medication was taken for at least 24 hours before the study. Initially the vital capacity (VC) and the forced expiratory volume in one second $\left(\mathrm{FEV}_{1}\right)$ were measured with a 13.5 litre Benedict-Roth spirometer. Predicted values of VC were obtained from the data of Cotes. ${ }^{10}$ About one hour later the effects of deep inspiration were examined with the subject seated in a volume displacement body plethysmograph $^{11}$; the respiratory resistance (Rrs) was measured by the oscillation technique,,$^{12}$ while the volume change within the plethysmograph was monitored by a Krogh spirometer and Sanborn linear transducer. A sine wave of frequency $3 \mathrm{~Hz}$ was generated at the mouth by a loudspeaker box system. ${ }^{12}$ The mouth pressure relative to ambient pressure was measured with a differential pressure transducer (Validyne, MP45 $\pm 50 \mathrm{~cm} \mathrm{H}_{2} \mathrm{O}$ ) and air flow at the mouth $(\dot{V})$ with a Fleisch pneumotachograph and differential transducer (Validyne, MP45 $\pm 5 \mathrm{~cm}$ $\mathrm{H}_{2} \mathrm{O}$ ). The calculation of respiratory resistance from Pao and $\dot{V}$ was continuously performed by an analogue computer using the method of Hyatt et $a l .{ }^{13}$ To deliver an aerosol of a bronchoconstrictor or bronchodilator, two Vaponephrin nebulisers (USV Pharmaceutical Corporation) that delivered $0.15 \mathrm{ml}$ of solution per minute were connected between the mouthpiece and pneumotachograph. A constant bias flow of $0.41 \mathrm{~s}^{-1}$ was introduced between the mouthpiece and the nebuliser to minimise dead space ventilation. Mouth flow, mouth pressure, volume change, and respiratory resistance were recorded on a four channel direct writing recorder system (Sanei, Japan).

For assessment of the effect of flow rate during deep inspiration in normal subjects, the protocol was as follows. After functional residual capacity (FRC) became steady the subject inspired fully from FRC to total lung capacity (TLC) and expired again to FRC with either a slow deep inspiration (SDI, mean flow 0.22 (SEM 0.02) $1 \mathrm{~s}^{-1}$ ) or a rapid deep inspiration (RDI, mean flow $\left.3.62(0.22) \mathrm{l} \mathrm{s}^{-1}\right)$. The flow during expiration from TLC to FRC was comparable to that during inspiration with each manoeuvre. Slow and rapid deep inspirations were performed in random order. FRC values before and after each deep inspiration were within 0.21 of each other. Respiratory resistance was measured continuously for at least two minutes before each manoeuvre and for five minutes afterwards. Further deep inspirations were performed at intervals of about 10 minutes, when respiratory resistance had returned to its baseline value before deep inspiration. The effects of slow and rapid deep inspiration were each examined two or three times, and average values of respiratory resistance were used for analysis. Then during tidal breathing each normal subject continuously inhaled an aerosol of a single concentration of methacholine $(6.25 \mathrm{mg} / \mathrm{ml})$ for about six minutes until the Rrs was twice the initial value. After inhalation of methacholine FRC usually increased by $0 \cdot 4-0 \cdot 71$. Rrs after slow and rapid deep inspiration was then measured again as described above.

In the asthmatic subjects the effects of slow and rapid deep inspiration on baseline Rrs were studied in the same way as in the normal subjects. In 13 of the 22 asthmatic subjects, the studies were repeated after methacholine $(6.25 \mathrm{mg} / \mathrm{ml})$ had been inhaled for about one minute - that is, until there had been a twofold increase in Rrs. This increased FRC by $0 \cdot 5-0 \cdot 8$ litre.

To examine the contribution of airway sensory receptors to the effects of different rates of inspiratory flow, studies were also performed (after the airways had been anaesthetised) in four normal subjects with methacholine induced bronchoconstriction and four asthmatic subjects who had transient bronchoconstriction after deep inspiration. ${ }^{8}$ An aerosol of $4 \%$ lignocaine was administered to these subjects with the nebuliser described above over a 15 minute period during tidal breathing with continuous monitoring of Rrs, which showed that lignocaine itself had no measurable effect. At the end of the measurement the subject inhaled five deep breaths of an aerosol of $10 \%$ citric acid and the absence of cough confirmed the adequacy of airway anaesthesia. ${ }^{14}$

In additional experiments 12 of the 22 asthmatic subjects had a methacholine provocation on a separate occasion three or four days later. Nine in this group belonged to the group in which the flow effects of deep inspiration had been studied after methacholine induced bronchoconstriction as described above. Methacholine provocation tests in these additional studies were performed by a previously reported technique, ${ }^{15}$ which allows construction of dose response curves of Rrs during the continuous inhalation of methacholine in stepwise incremental concentrations from 0.049 to 25.0 $\mathrm{mg} / \mathrm{ml}$. Rrs was again measured by the oscillation method as described above. From the dose response curve we obtained the cumulative dose of methacholine (Dmin) required to initiate a decrease in respiratory conductance (Grs, reciprocal of respiratory resistance). Dmin was used as the index of bronchial sensitivity and expressed in units, as in the work of Chai et l $^{16}$ - that is, one unit represents the inhalation for one minute of an aerosol of 1.0 $\mathrm{ml} / \mathrm{ml}$ during tidal breathing. ${ }^{15}$ We then looked at the effects of slow and rapid deep inspiration on respiratory resistance without drug induced 
Pulmonary function in normal and asthmatic subjects (means with SEM in parentheses)

\begin{tabular}{|c|c|c|c|c|}
\hline & No of subjects & $\begin{array}{l}V C(\% \text { predicted }) \\
(S D)\end{array}$ & $\underset{(S D)}{F E V, I V C \%}$ & $\begin{array}{l}\text { Rrs } \\
\left(\mathrm{cm} \mathrm{H} \mathrm{H}_{2} \mathrm{Ol}^{-1} \mathrm{~s}\right)\end{array}$ \\
\hline $\begin{array}{l}\text { Normal } \\
\text { Bronchial asthma } \\
\text { p }\end{array}$ & $\begin{array}{r}9 \\
22\end{array}$ & $\begin{array}{l}107 \cdot 9(5 \cdot 5) \\
103 \cdot 8(2 \cdot 3) \\
\text { NS }\end{array}$ & $\begin{array}{l}87.3(1.2) \\
72.2(3.0) \\
<\quad 0.01\end{array}$ & $\begin{aligned} & 2.58(0.18) \\
& 3.42(0.15) \\
< & 0.01\end{aligned}$ \\
\hline
\end{tabular}

VC_-vital capacity; FEV_-forced expiratory volume in one second; Rrs_respiratory resistance; NS—not significant.
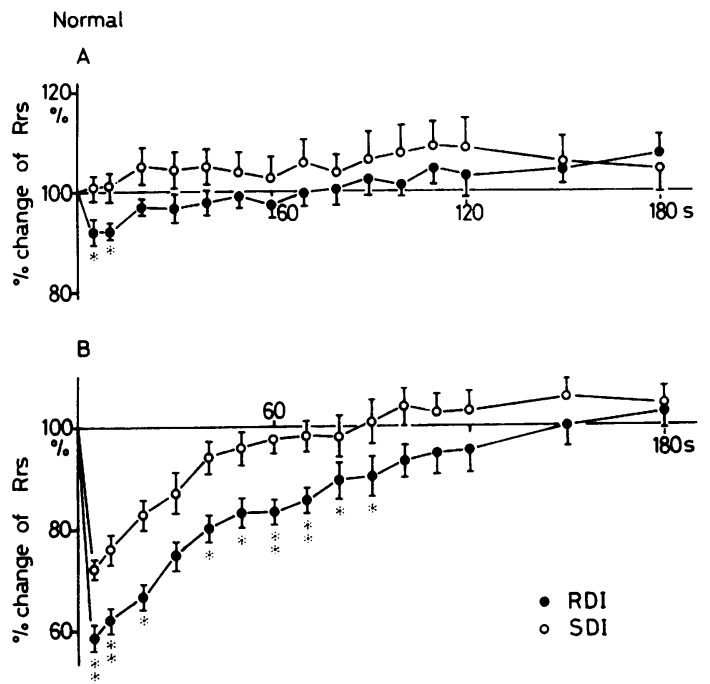

Fig 1 Effects of slow deep inspiration $(S D I)(O)$ and rapid deep inspiration (RDI) (@) on change in respiratory resistance (Rrs) in nine normal subjects. Rrs, expressed as the percentage of preinspiration control value (ordinate), was plotted in relation to time (seconds) after deep inspiration (abscissa). The upper panel $(A)$ shows the results before methacholine inhalation and the lower panel (B) shows those after methacholine inhalation. Values are presented as means and standard errors. ${ }^{,},{ }^{* *}$ Significant difference at the corresponding periods between RDI and $S D I\left({ }^{*} p<0.05 ;^{* *} p<0.01\right)$.

bronchoconstriction in relation to bronchial sensitivity to methacholine. At the end of the test bronchoconstriction was reversed by inhalation of a $2 \%$ metaproterenol aerosol for 1 to 2 minutes.

Statistical analysis was performed with Student's $t$ test or analysis of variance. The level for significant differences was taken as $p<0 \cdot 05$. Values are given as means with standard errors in parentheses.

\section{Results}

The table shows baseline spirometric data and respiratory resistance in the normal and asthmatic subjects. The FEV/VC (\%) was significantly lower and respiratory resistance higher in the asthmatic than in the normal subjects $(p<0 \cdot 01)$.

Figure 1 shows the time course of changes in respiratory resistance after deep inspiration in the normal subjects. Under baseline conditions (fig 1A) all values of respiratory resistance were within $20 \%$ of the control values, but respiratory resistance after rapid deep inspiration decreased significantly compared with the corresponding values after slow deep inspiration in the first 10 seconds (paired $t$ test, $\mathrm{p}<$ 0.05 ). There were no differences between the values at 20 and at 180 seconds after the deep inspiration. In contrast, the greater respiratory resistance (maximum values $\left.5.08(0.36) \mathrm{cm} \mathrm{H}_{2} \mathrm{Ol}^{-1} \mathrm{~s}\right)$ after methacholine inhalation fell immediately after deep inspiration, with a gradual return towards control levels within about 80 and 150 seconds of slow and rapid deep inspiration respectively (fig. 1B). The mean maximal reduction of respiratory resistance was $20 \%$ and $42 \%$ at 5 seconds after slow and rapid deep inspiration, and the reduction of respiratory resistance after rapid deep inspiration was significantly greater than after slow deep inspiration (analysis of variance, $\mathrm{p}<0.05$ ).

In the asthmatic subjects without artificially induced bronchoconstriction there was a significant inverse correlation between the maximal change in respiratory resistance after rapid deep inspiration and $\mathrm{FEV}_{\mathrm{t}} / \mathrm{VC}(\mathrm{r}=-0.51, \mathrm{p}<0.02)$ but not after slow deep inspiration $(r=-0.37,0.05<p<0.1)$. This shows that the more severe the initial obstructive impairment before deep inspiration the larger the increase of respiratory resistance with rapid deep inspiration. We therefore divided the asthmatic subjects into two groups: one with FEV/VC greater than $80 \%(\mathrm{FEV} / \mathrm{VC} 84.1 \%(1.1 \%))$ and the other with $\mathrm{FEV} / \mathrm{VC}$ less than $80 \%(62 \cdot 2 \%$ $(3.2 \%)$ ). In the former group (fig $2 \mathrm{~A}$ ) there was no significant change in respiratory resistance after either slow or rapid deep inspiration. In contrast, in asthmatics with baseline $\mathrm{FEV}_{\text {/ }} / \mathrm{VC}$ less than $80 \%$ (fig 2B) both slow and rapid deep inspiration resulted in an increase in respiratory resistance, and the increase was significantly greater after rapid than that after slow deep inspiration (analysis of variance, $p<0 \cdot 05)$. In 13 asthmatic subjects in whom bronchoconstriction was induced by a single dose of methacholine the mean (SEM) increase in respiratory resistance $\left(\mathrm{cm} \mathrm{H}_{2} \mathrm{O} \mathrm{l}^{-1} \mathrm{~s}^{-1}\right)$ was from 3.29 $(0.20)$ to $6.30(0.34)$. In this group with artificially 

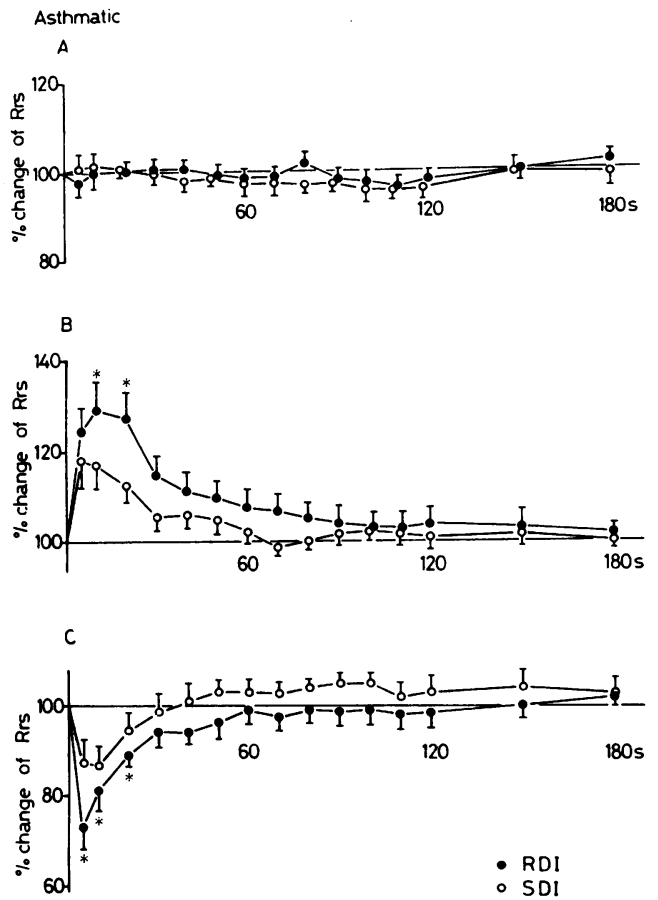

Fig 2 Effects of slow (O) and rapid (O) deep inspiration (SDI and RDI) on changes in Rrs in asthmatic subjects. $A$ - flow effects on Rrs in 10 asthmatic subjects with normal basal bronchomotor tone (FEV/VC over $80 \%$ ). The flow effects showed no significant difference between $R D I$ and $S D I$. B-flow effects on Rrs in 12 asthmatic subjects with spontaneous airway narrowing (FEV/VC less than 80\%). $R$ rs increased after both $R D I$ and $S D I$, and the increase after $R D I$ was significantly greater than that after SDI. C-flow effects on Rrs in 13 asthmatic subjects with

bronchoconstriction artificially increased by a single dose of methacholine. Rrs decreased immediately after both RDI and SDI, and the decrease was significantly greater after RDI than after SDI in the first 20 seconds. Values are presented as means and standard errors. ${ }^{*}$ Significant difference at the corresponding periods between $R D I$ and SDI at $p<0.05$.

induced bronchoconstriction an immediate decrease of respiratory resistance was found after both slow and rapid deep inspiration (fig 2C) and, as in the normal subjects, the reduction of respiratory resistance was significantly greater after rapid than after slow deep inspiration in the first 20 seconds (paired $t$ test, $\mathrm{p}<0.05$ ). Variations in expiratory flow rate had no effect on the results.

Figure 3 shows the effect of slow and rapid deep inspiration on bronchomotor tone before and after lignocaine in four normal subjects with methacholine induced bronchoconstriction and in four asthmatic subjects. In normal subjects the reduction in respiratory resistance after deep inspi- ration at both rapid and slow flow rates was significantly inhibited by lignocaine aerosol. The effect of rapid deep inspiration was significantly greater than that of slow deep inspiration in the first 30 seconds both before and after airway anaesthesia (analysis of variance, $\mathrm{p}<0 \cdot 05$ ). In the asthmatic subjects the transient increase in respiratory resistance after deep inspiration at both flow rates was also inhibited by lignocaine.

In 12 asthmatic subjects in whom dose response curves for methacholine were obtained the relationships between the maximal changes in respiratory resistance after deep inspiration without drug induced bronchoconstriction and bronchial sensitivity to methacholine (Dmin) were compared (fig 4). The change in respiratory resistance expressed as a proportion of its control value after both slow and rapid deep inspiration showed a significant inverse correlation with $\log \operatorname{Dmin}(p<0.05$ and $p<0.01$ respectively). The regression coefficients were not significantly different.

\section{Discussion}

There were four main findings in this study. Firstly, in asthmatic subjects with significant airflow obstruction a rapid deep inspiration induced a greater increase in bronchomotor tone than a slow inspiration and the magnitude of the effect of rapid deep inspiration was dependent on the degree of baseline airway narrowing. Secondly, both the bronchoconstrictor and the bronchodilator effects of deep inspiration on bronchomotor tone were partially inhibited by airway anaesthesia. Thirdly, bronchoconstriction after both rapid and slow deep inspiration was related to bronchial sensitivity as assessed by the threshold value in a methacholine provocation test. Finally, in both normal and asthmatic subjects rapid deep inspiration produced greater inhibition of methacholine induced bronchoconstriction than did slow deep inspiration.

To detect the bronchomotor tone we measured respiratory resistance using an oscillation method ${ }^{12}$ rather than the more usual specific airway resistance, ${ }^{1-3}$ because it was easy to monitor simultaneously both volume change and change of respiratory resistance during testing without any cooperation of the patients such as a panting manoeuvre. Since respiratory resistance reflects the total resistance of the respiratory system, we had to consider the effect of tissue or chest wall resistance or both on the change of respiratory resistance. As functional residual capacity and tidal volume, however, were kept constant before and after deep inspiration, any change of lung tissue and chest wall resistance would be negligible. Changes in laryngeal resistance might 

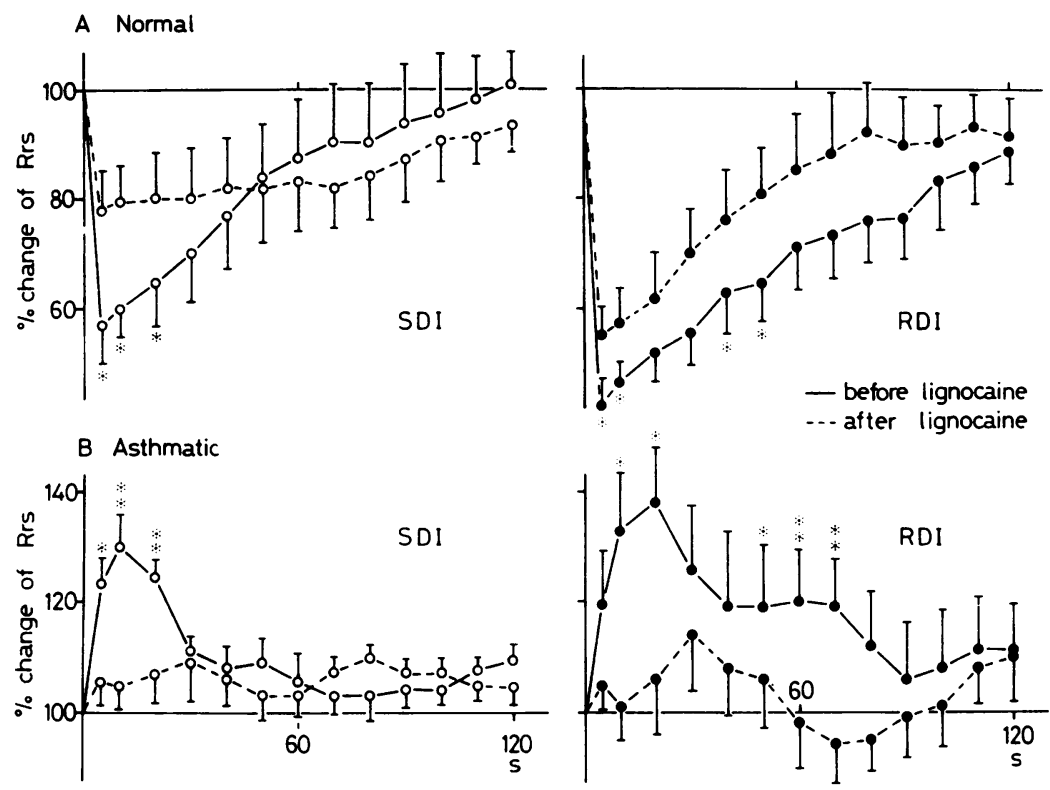

Fig 3 Effect of lignocaine aerosol on bronchomotor tone after slow deep inspiration $(S D I)(O)$ and rapid deep inspiration ( $R D I)(O)$ in four normal subjects with methacholine induced bronchoconstriction $(A)$ and in four asthmatic subjects $(B)$. The continuous and dashed lines show the changes in respiratory resistance (Rrs) induced by deep inspiration before and after lignocaine aerosol inhalation respectively. The effects of deep inspiration before anaesthesia in the four normal subjects illustrated were greater than those in the group as a whole (fig I) but the differences were not significant for either SDI or RDI.

*, ** Significant difference before and after lignocaine at $p<0.05$ and $p<0.01$ respectively.

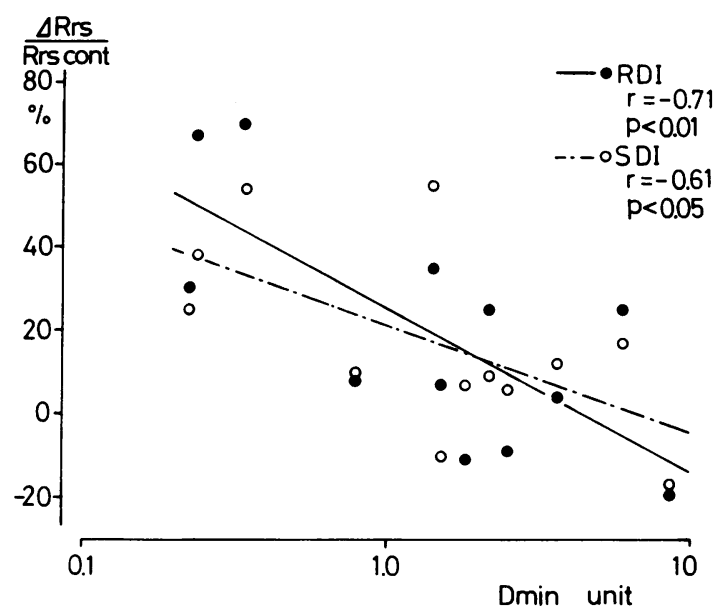

Fig 4 Relationships between the effects of slow deep inspiration (SDI) (O) and rapid deep inspiration (RDI) on baseline bronchomotor tone and sensitivity to methacholine in asthmatic subjects. The ordinate indicates the maximal change in Rrs after deep inspiration expressed by the percentage of control Rrs. Abscissa (logarithmic scale) indicates the cumulative dose of methacholine required to initiate an increase in Rrs (Dmin). The greater the sensitivity to methacholine (lower Dmin) the greater the increase in Rrs after either a rapid or a slow deep inspiration.

Regression lines: $S D I y=21 \cdot 0-26 \cdot 2 x$,

$$
R D I y=25 \cdot 1-39 \cdot 3 x \text {, }
$$

$$
\text { where } x=\log \text { Dmin and } y=\frac{\Delta R r s}{\text { control Rrs }} \text {. }
$$

also contribute to the change of respiratory resistance after deep inspiration in view of the recent evidence suggesting upper airway narrowing in some asthmatic patients. ${ }^{17}$ Further study would therefore be needed to show how laryngeal resistance changes after deep inspiration in normal or asthmatic subjects. When a subject coughed, swallowed saliva, or temporarily held his breath, respiratory resistance was transiently variable, presumably owing to glottic narrowing; but otherwise the measurements were stable.

One possible explanation for the bronchoconstrictor effect of deep inspiration in asthmatic subjects with spontaneous airway narrowing is that the deep inspiration might mechanically stimulate the irritant receptors that are located all around the airways. ${ }^{18}$ We have shown that a fast flow rate during deep inspiration induced more bronchoconstriction than a slow flow rate, which might be due to greater stimulation of irritant receptors at higher flows since these will be accompanied by a greater transmural pressure across the constricted airway. If so these effects of deep inspiration should be inhibited by airway anaesthesia; Camporesi $e t a^{8}$ reported that local anaesthesia of the airway can block both irritant receptors and stretch receptors and the present study showed that the flow rate effects of deep inspiration were attenuated after lignocaine inhalation (fig 3B). The results therefore suggest that the differential effect of slow and rapid deep inspiration may be at least in part a vagal 
reflex. Alternative explanations for the bronchoconstrictive effect are that the greater negativity of the perivascular interstitial fluid pressure during lung inflation could cause interstitial oedema and narrowing of the peripheral airways, ${ }^{19}$ or that a release of prostaglandin $\mathrm{F}_{2 \alpha}$ might induce bronchoconstriction after deep inspiration. ${ }^{20}$ It is not known whether either of these is dependent on the inspiratory flow rate.

The bronchodilator effect of rapid and slow deep inspiration in both normal and asthmatic subjects whose bronchomotor tone has been artificially increased by methacholine may be explicable by a faster flow rate during deep inspiration, stimulating stretch receptors ${ }^{21}$ and inducing more bronchodilatation, as suggested by Beaupré and Orehek. ${ }^{7}$ Our results with lignocaine might support this explanation, at least in part. The fact, however, that the flow effect of deep inspiration was seen even when the airways were anaesthetised suggests other mechanisms, such as hysteresis of the airway smooth muscle itself. Sasaki and Hoppin ${ }^{22}$ observed that the length-tension hysteresis loop of airway smooth muscle strips with increased bronchomotor tone tended to be larger than with relaxed smooth muscle. The difference between pulmonary resistance at a given lung volume after deflation from TLC and during inflation to TLC would therefore be greater in the constricted state. Furthermore, as a faster inspiratory flow during inspiration would be accompanied by a greater transmural distending pressure of the airway during inspiration the airway would be stretched more, which would increase airway hysteresis. Release of bronchodilator chemical mediators such as prostaglandin $\mathrm{E}_{2}^{21}$ during lung inflation may also contribute to the change of bronchomotor tone after deep inspirations. Again, however, the effects of flow on release of prostglandin $E_{2}$ are not known.

In normal and asthmatic subjects with normal bronchomotor tone there was little change in respiratory resistance after either slow deep inspiration or rapid deep inspiration. With normal bronchomotor tone inspiratory flows during deep inspiration would be expected to have little effect on the stimulation of neural receptors or hysteretic behaviour of the airways, etc.

We showed that the transient increases in respiratory resistance after both slow and rapid deep inspiration were significantly correlated with bronchial sensitivity (Dmin). These results seem to be at variance with the data of Fish et al, ${ }^{2}$ who found that there was no correlation between methacholine sensitivity and the amount of fall in specific conductance or in FEV, after deep inspiration in asthmatic subjects with spontaneous bronchomotor tone. The method of obtaining dose response curves and the definition of bronchial sensitivity are possible reasons for this discrepancy. We used the minimum threshold of the dose response curve as the index of the bronchial sensitivity, ${ }^{16}$ while Fish et al used the cumulative dose required to produce a $35 \%$ fall or $20 \%$ fall in specific conductance or in $\mathrm{FEV}_{1}$ respectively. ${ }^{2}$ We also examined the cumulative dose of methacholine required to produce a $35 \%$ fall in Grs and found that this index was not correlated with bronchial sensitivity. On the basis of our results we would suggest that hyperreactivity of irritant receptors is one of the factors in increasing bronchial sensitivity to methacholine. The present study suggests that the influence of deep inspiration on FEV measurements could be minimised if the forced expiration were preceded by a slow inspiration.

We wish to express our gratitude for the preparation of this manuscript to Ms S Omori and Mrs B Hayashi.

\section{References}

' Gayrard P, Orehek J, Grimaud C, Charpin J. Bronchoconstrictor effects of a deep inspiration in patients with asthma. Am Rev Respir Dis 1975;111:433-9.

${ }^{2}$ Fish JE, Peterman VI, Cugell DW. Effect of deep inspiration on airway conductance in subjects with allergic rhinitis and allergic asthma. J Allergy Clin Immunol 1977;60:41-6.

${ }^{3}$ Orehek J, Nicoli MM, Delpierre S, Beaupré A. Influence of the previous deep inspiration on the spirometric measurement of provoked bronchoconstriction in asthma. Am Rev Respir Dis 1981;123:269-72.

${ }^{4}$ Nadel JA, Tierney DF. Effect of a previous deep inspiration on airway resistance in man. $J$ Appl Physiol 1961;16:717-9.

${ }^{5}$ Widdicombe JG, Nadel JA. Reflex effects of lung inflation on tracheal volume. J Appl Physiol 1963;18:681-6.

- Nadel JA. Autonomic regulation of airway smooth muscle. In: Nadel JA, ed. Physiology and pharmacology of the airways. New York: Marcel Dekker, 1980;21757.

${ }^{7}$ Beaupré A, Orehek J. Factors influencing the bronchodilator effect of a deep inspiration in asthmatic patients with provoked bronchoconstriction. Thorax 1982;37:124-8.

' Camporesi EM, Mortola JP, Sant' Ambrogio F, Sant' Ambrogio G. Topical anesthesia of tracheal receptors. J Appl Physiol: Respirat Environ Exercise Physiol 1979;47:1123-6.

"American Thoracic Society. Chronic bronchitis, asthma and pulmonary emphysema. Am Rev Respir Dis 1962;85:762-8.

${ }^{10}$ Cotes JE. Lung function, 4th ed. Oxford: Blackwell, 1979:371-7.

" Mead J. Volume-displacement body plethysmograph for respiratory measurements in human subjects. $J$ Appl Physiol 1960;15:736-40. 
${ }^{12}$ Grimby G, Takishima T, Graham W, Macklem P, Mead $J$. Frequency dependence of flow resistance in patients with obstructive lung disease. $J$ Clin Invest 1968;47: 1455-65.

${ }^{13}$ Hyatt RE, Zimmerman IR, Peters GM, Sullivan WJ. Direct writeout of total respiratory resistance. J Appl Physiol 1970;28:675-8.

${ }^{14}$ Cross BA, Guz A, Jain SK, Archer S, Stevens J, Reynolds $F$. The effect of anaesthesia of the airway in dog and man: a study of respiratory reflexes, sensations and lung mechanics. Clin Sci Mol Med 1976;50:439-54.

is Takishima T, Hida W, Sasaki H, Suzuki S, Sasaki T. Direct-writing recorder of the dose-response curves of the airway to methacholine. Clinical application. Chest 1981;80:600-6.

${ }^{16}$ Chai H, Farr RS, Froehlich LA, et al. Standardization of bronchial inhalation challenge procedures. J Allergy Clin Immunol 1975;56:323-7.

${ }^{17}$ Lisboa C, Jardim J, Angus E, Macklem PT. Is extrathoracic airway obstruction important in asthma? Am Rev Respir Dis 1980;122:115-21.

18 Sant' Ambrogio G, Remmers JE, De Groot WJ, Callas G, Mortola JP. Localization of rapidly adapting receptors in the trachea and main stem bronchus of the dog. Respir Physiol 1978;33:359-66.

${ }^{19}$ Hida W, Inoue H, Hildebrandt J. Lobe weight gain and vascular, alveolar, and peribronchial interstitial fluid pressures. J Appl Physiol: Respirat Environ Exercise Physiol 1982;52:173-83.

${ }^{20}$ Smith A, Cuthbert MF. Antagonistic action of aerosols of prostaglandin $\mathrm{F}_{2 \alpha}$ and $\mathrm{E}_{2}$ on bronchial muscle tone in man. $B r$ Med $J$ 1972; iii:212-3.

${ }^{21}$ Davis HL, Fowler WS, Lambert EH. Effect of volume and rate of inflation and deflation on transpulmonary pressure and response of pulmonary stretch receptors. Am J Physiol 1956;187:558-66.

${ }^{22}$ Sasaki H, Hoppin FG jun. Hysteresis of contracted airway smooth muscle.J Appl Physiol: Respirat Environ Exercise Physiol 1979;47:1251-62. 